\title{
A COMPREHENSIVE STUDY OF DIAGNOSIS FAULTS TECHNIQUES OCCURRING IN PHOTOVOLTAIC GENERATORS
}

\author{
Selma Tchoketch Kebir ${ }^{1,2^{*}-N a w a l ~ C h e g g a g a ~}{ }^{3}$ - Mohamed Salah Ait Cheikh ${ }^{1}$ - Mourad Haddadi ${ }^{1}$ - \\ Hachemi Rahmani ${ }^{1,2}$
}

\begin{abstract}
${ }^{1}$ Laboratoire de Dispositifs de Communications et de Conversion Photovoltaique, Electronic Departement, Ecole Nationale Polytechnique, Algiers 16000, Algeria

${ }^{2}$ Unité de Développement des Equipements Solaires, UDES/Centre de Développement des Energies Renouvelables, CDER, Bou-Ismail, 42415, W. Tipaza, Algeria

${ }^{3}$ Laboratory of Electrical Systems and Remote control, Electronic Departement, University Saad Dahleb of Blida, Po Box 270 Route de Soumaa, Blida 09000, Algeria
\end{abstract}

\begin{tabular}{l} 
ARTICLE INFO \\
\hline Article history: \\
Received: 11.08 .2020$. \\
Received in revised form: 22.12 .2020$. \\
Accepted: 14.01 .2021$. \\
\hline Keywords: \\
Photovoltaic generator \\
Degradations \\
Faults detection \\
Inspection \\
Diagnosis \\
Supervision \\
\hline DOI: https://doi.org/10.30765/er.1714
\end{tabular}

\section{Introduction}

In recent times, there has been an emergent awareness in promoting alternate energies that are inexhaustible and environment friendly compared to energies derived from fossil deposits such as oil, coal, and natural gas. Alternate energy includes all renewable resources that do not implicate fossil fuels, such as solar, wind, geothermal, hydroelectric, and biomass. Solar photovoltaic (PV) energy is one of the most commonly spread renewable energy across the globe, where it has attained a cumulative capacity of $635 \mathrm{GW}$ by the end of 2019 $[1]$.

Applications of solar PV energy are subject to failures and damages during their life cycle [2,3]. Hence, to protect the system, avoid any damage, guarantee longevity, ensure safe operation and avoid loss of efficiency, suitable diagnosis is crucial. Different causes (internal, external, and ageing effect) [2], [4], [5] imply several defects in photovoltaic plants. Internal PV faults originate from the PV plant itself and include all components failures such as generators, cabling, converters, protections, batteries, inverter and data acquisition system [4]. External PV faults, which lead to several degradations [6] and annual power losses [7,8], are due to outer unfavourable conditions, such as shading effect [9], high temperature [10], low irradiance, high humidity, suboptimal tilt or orientation, corrosion [11] and dirt, snow, and dust accumulation in surface [12].

\footnotetext{
* Corresponding author.

E-mail address: selma.tchoketch_kebir@g.enp.edu.dz/tchoketch-kebir.selma@udes.dz
}

\begin{abstract}
Recently, many focuses have been done in the field of renewable energies, especially in solar photovoltaic energy. Photovoltaic generator, considered as the heart of any photovoltaic installation, the overall photovoltaic plant. Therefore, diagnosis techniques are required to ensure failures detection. They avoid dangerous risks, For these purposes, many recent studies have given focuses on this field. This paper summarizes a large number of such interesting kinds, several types of faults, and their major diagnosis techniques. Comparative studies and some critical analyses are given. Other trending diagnosis solutions are also discussed. A proposed neural of diagnosis techniques, using artificial intelligence. This method shows good results for modelling and diagnosing the healthy and faulty (shaded) photovoltaic array.
\end{abstract}


Many studies have focused only on faults occurring in the PV generator (cell, panel, string, and array) due to several hazards failures that can occur on it (electrical shock and fire risks) [13]. These faults can be classified into physical, environmental, and electrical faults [14]. Physical faults are caused by internal failures (damages on PV panel or on blocking and bypassing diode (BBP)) or external failures (cracks in PV panels, junction box (JB) damages or other degradations) [15]. Environmental faults are caused by soiling [16], permanent shading (Hot spot (HS)) [17], or temporary shading (Partial shading (PS)) [18]. Electrical faults [3], and their catastrophic threat [13] are caused by Open-Circuit (OC), Short-Circuit (SC) Line-to-Line Fault (LLF), Ground fault (GF), and Arc fault (AF).

To detect and identify abnormal conditions at early stages and reduce the risks associated with a long-term operation, fault detection and diagnosis (FDD) techniques for photovoltaic generator (PVG) are needed. Many research works have been focused on developing diverse FDD techniques, to guarantee efficient and intelligent monitoring and supervision in PV plants. This work deals with the main techniques developed, cited in the literature. Figure 1 shows the growing number of reference documents concerning the diagnosis of PV systems published since 2005. This shows how much research on this subject has increased over the years.

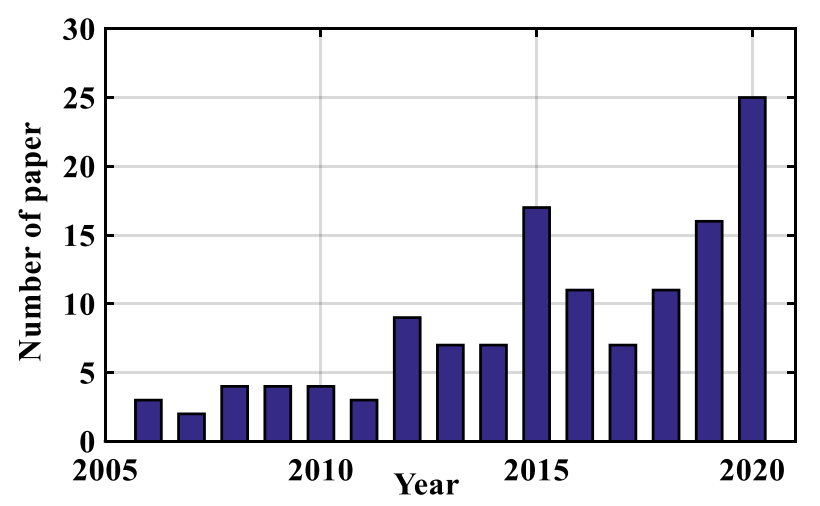

Figure 1. Growth of PV diagnosis published papers per year, since 2005.

The remaining of this paper is organized as follow: Section 2 presents details about the kinds of photovoltaic generators degradations. Section 3 gives details about the different types of faults occurring in PVG. Section 4 deals with the classification, from the literature, of fault detection and diagnosis techniques in PVG. Some envisaged diagnosis solutions are also highlighted. Section 5 presents with details the process of FDD techniques, focusing on a proposed Artificial intelligence (AI) based approach for the diagnosis of a frequent fault (shading) occurring suddenly in the PVG. Finally, section 6 gives a conclusion of this work.

\section{Kind of degradation in PVG}

Gradual deteriorations of PV plants components involve lower performances, power losses and hazardous risks. Several factors cause different degradations that can occur in a photovoltaic generator [5, 11, 19 and 20].

The major kinds of degradations are summarized as follows (Figure 2):
a) Oxidation phenomenon.
b) Corrosion phenomenon.
c) Metal corrosion phenomenon.
d) Dirt in PV panels.
e) Dust in PV panels.
f) Snow in PV panels.
g) Uniform and non-uniform soiling.
h) Brocken/shattered glass [15, 19].
i) Junction box degradations.
j) Mechanical breakage \& degradation of JB: burnt diode phenomenon.
k) Fire damage.
1) Temporary shading (PS). 
m) Discoloration of Ethylene vinyl acetate (EVA) phenomenon.

n) Detachment of EVA phenomenon.

o) Snail tracks phenomenon.

p) Back sheet-chalking phenomenon.

q) Catastrophic bond failure phenomenon.

r) Degradation of antireflection coating of photovoltaic cells, caused by water vapor ingress.

s) Burn marks phenomenon.

t) Delamination phenomenon.

u) Bubbles phenomenon.

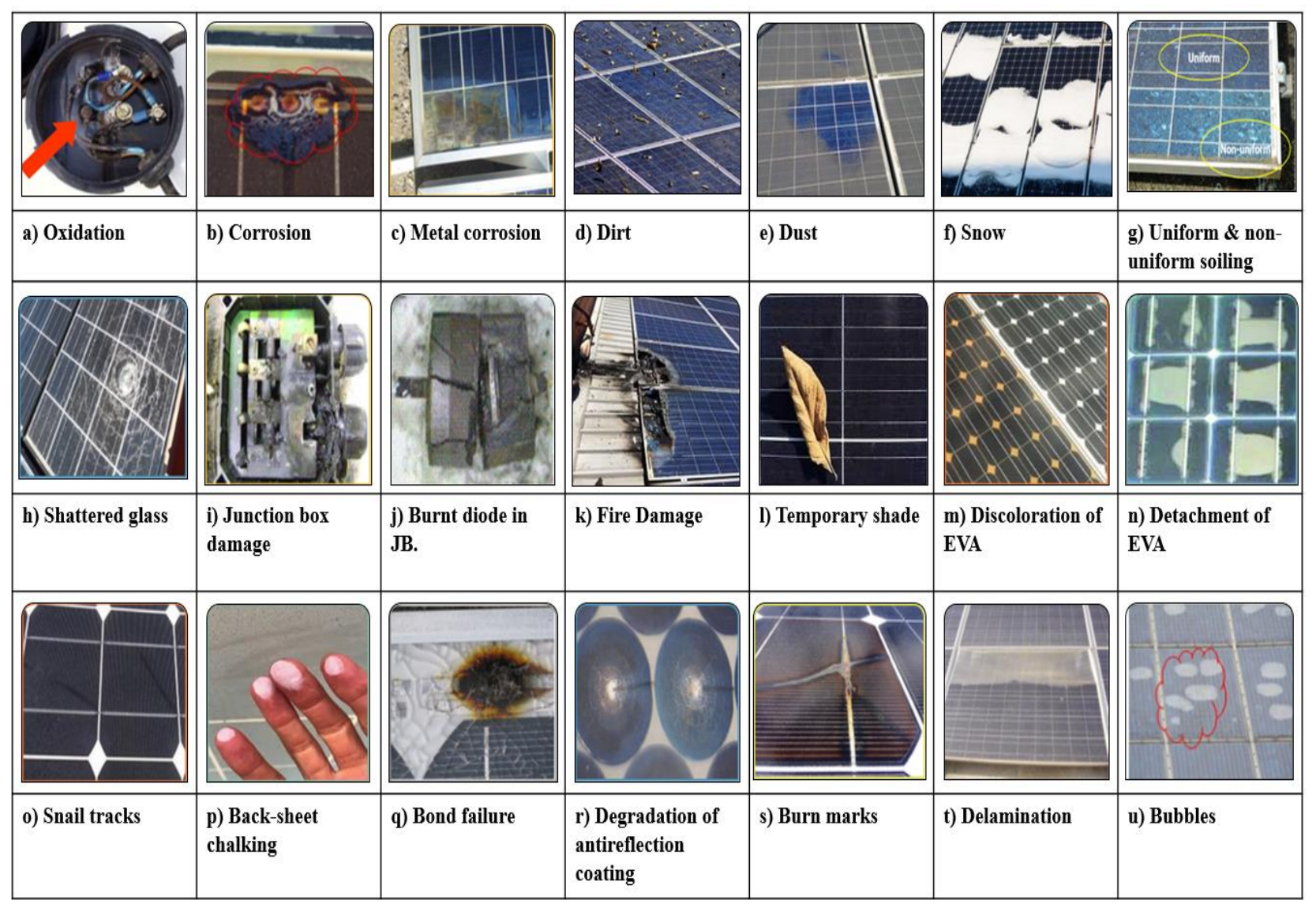

Figure 2. Kinds of degradation in a photovoltaic generator.

Other PV degradations exist such as encapsulation failures, improper installations, wiring mistakes, leakage currents, installations damages, manufacturing defects, and transportation destructions.

\section{Types of faults in PVG}

The non-linear behavior of the PV generator and its intermittent operation due to environmental conditions (temperature and irradiance), involves the occurrence of many faults. Therefore, it is necessary to find out the techniques to detect them. The following Figure 3 illustrates some Current-Voltage $(I-V)$ characteristics curves. The red curve represents the normal $I-V$ characteristic whereas the other ones represent faulty $I-V$ characteristics. 


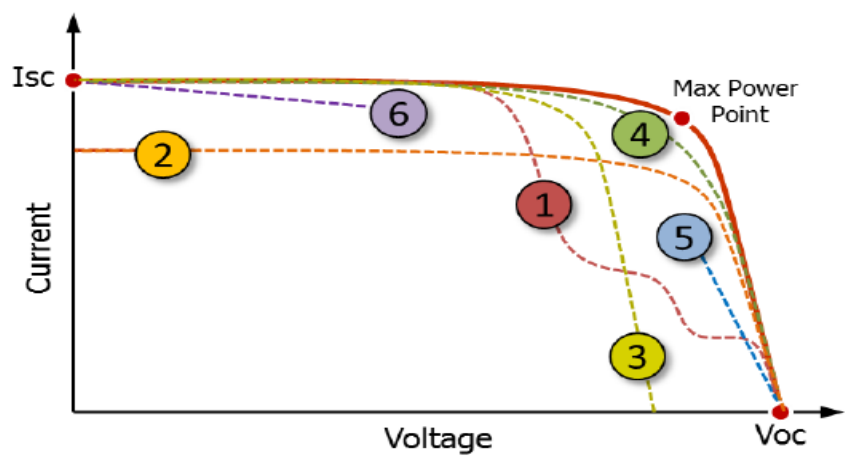

Figure 3. I-V curves under various types of faults.

The six deviations curves have multiple causes, which are detailed bellow.

1) Shading
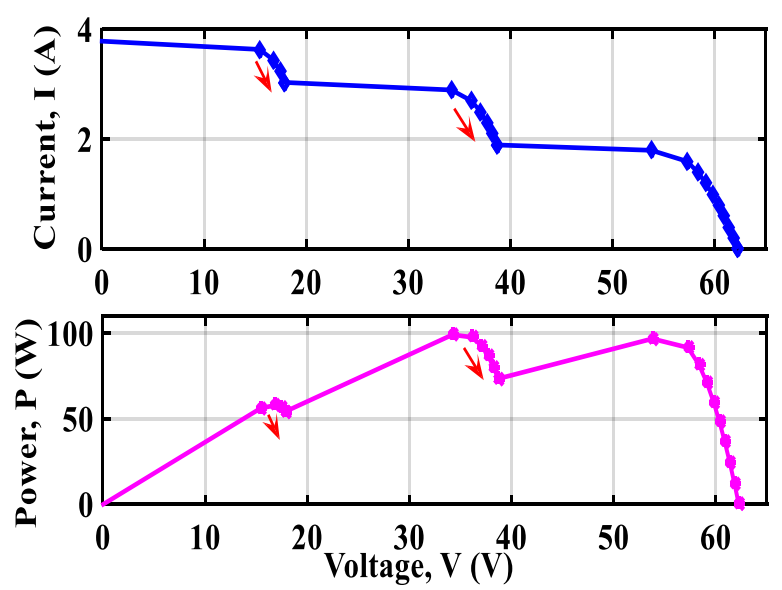

Figure 4. I-V and Power-Voltage $(P-V)$ characteristics of $P V$ generator with shading fault effect.

Shading fault may involve severe damages [18]. It can decrease the current, voltage, and power at the Maximum power point (MPP): $I_{M P P}, V_{M P P} \& P_{M P P}$ (Figure 4).

2) Open-Circuit (OC)

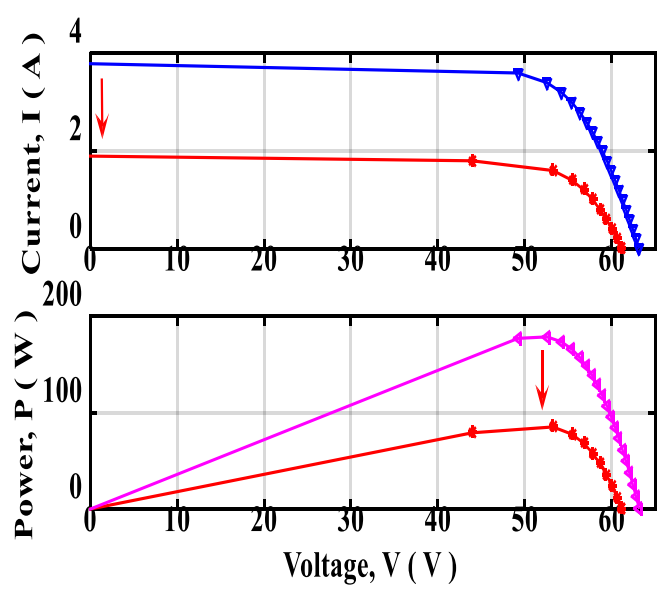

Figure 5. I-V and P-V characteristics with Open-Circuit fault effect. 
Open-circuit fault affect short-circuit and MPP currents $\left(I_{S C}, I_{M P P}\right)$, causing a decline of their values (Figure 5). Cracks in PV cells, weakness, due to thermal stress, and wind loading lead to interconnection, which affects the occurrence of Open-Circuit fault [21]. Figure 6 gives an example of OC fault in a PV string.

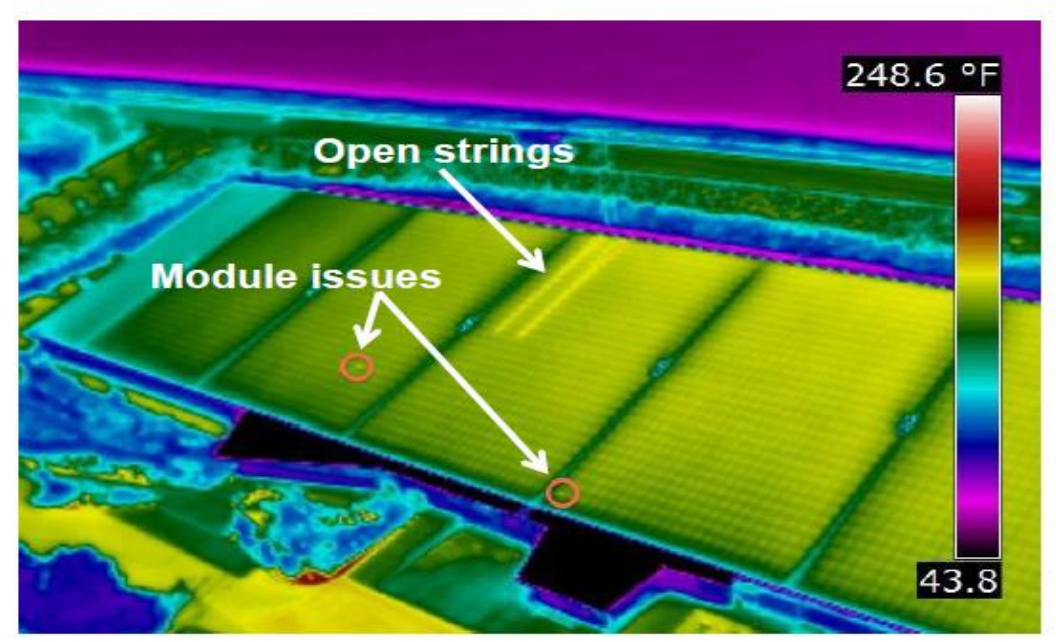

Figure 6. Example of Open-Circuit in a PV string (OC).

3) Short-Circuit (SC)

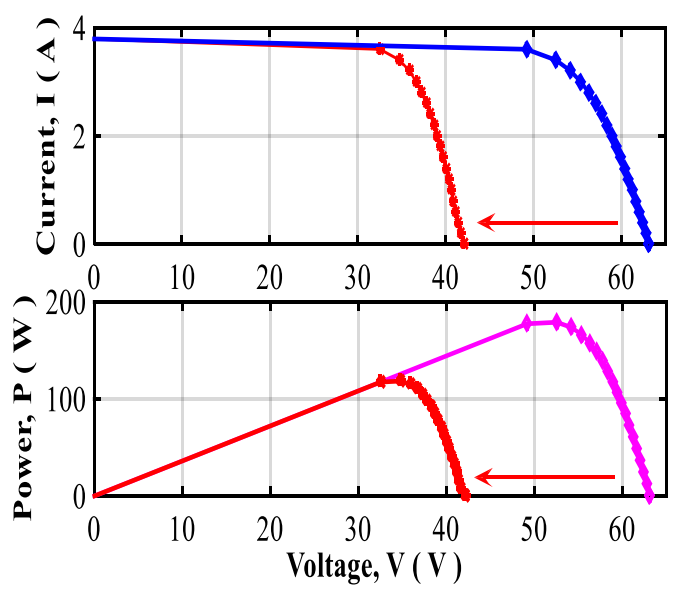

Figure 7. I-V and P-V characteristics with Short-Circuit fault effect.

Figure 7 shows that Short-Circuit fault reduces PV voltages at Open-Circuit and MPP $\left(V_{O C}, V_{M P P}\right)$. It appears at PV cell interconnections causing excessive heating (Figure 8). Besides, it can also be caused by bad wiring during installation or handling [21]. 


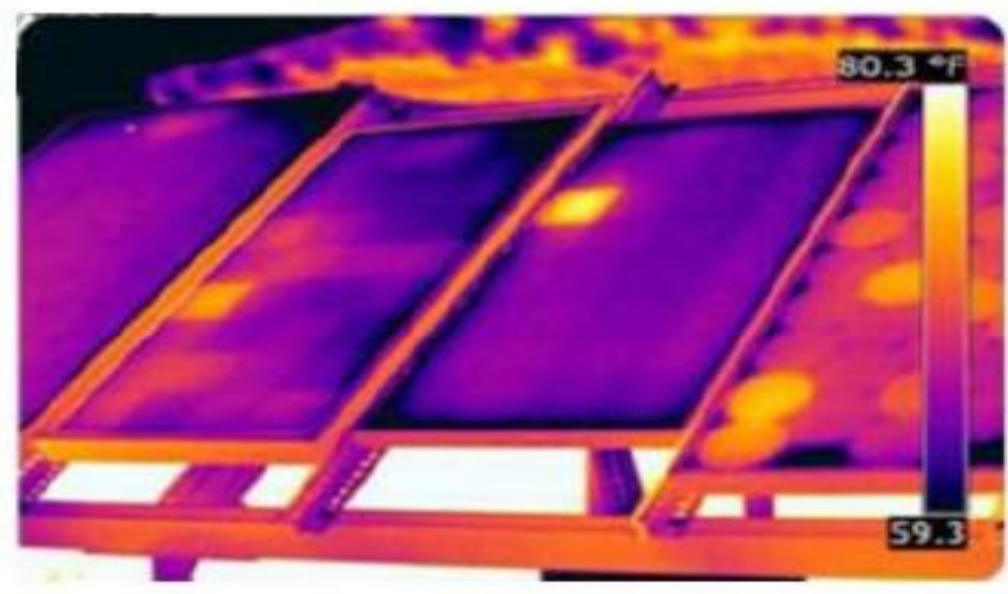

Figure 8. Example of Short-Circuited PV cell (SC).

4) Abnormal degradations

Abnormal degradations reduce PV generator efficiency (Figure 9). They are mainly due to the ageing effect in a harsh environment condition.

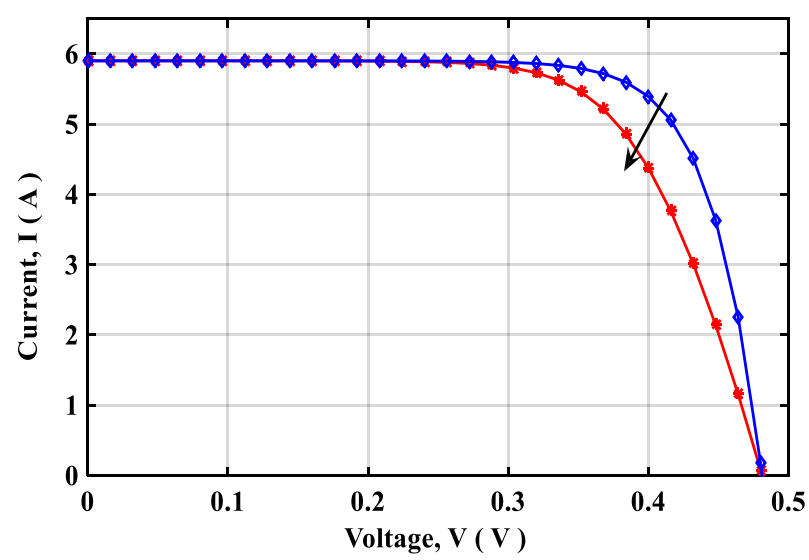

Figure 9. Effect of abnormal degradations in the I-V characteristic.

5) Increasing series resistance $\left(R_{S}\right)$

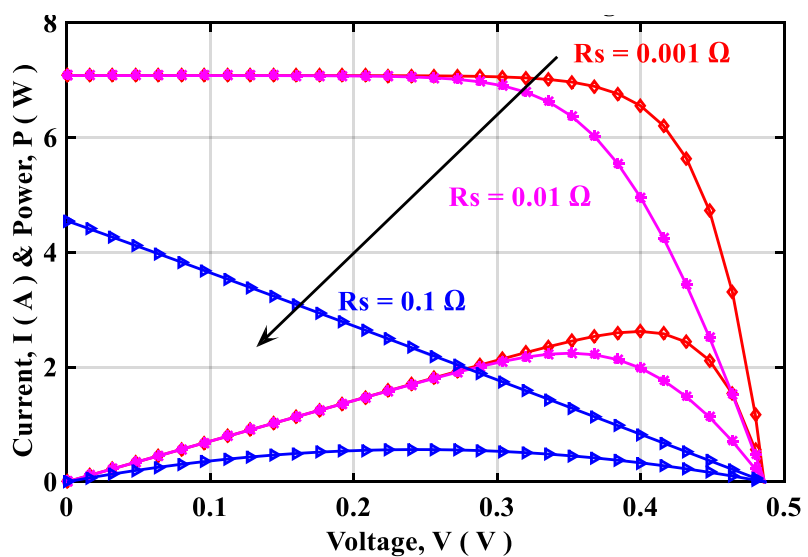

Figure 10. Effect of increasing in series resistance on the I-V and P-V characteristics. 
Degradations such as bond failure and resistive heating cause an influence on series resistance value. From Figure 10 one can see that the increase in series resistance value causes a decrease at the slope of OC (vertical leg) and then severe damage.

6) Decreasing shunt resistance $\left(R_{s h}\right)$

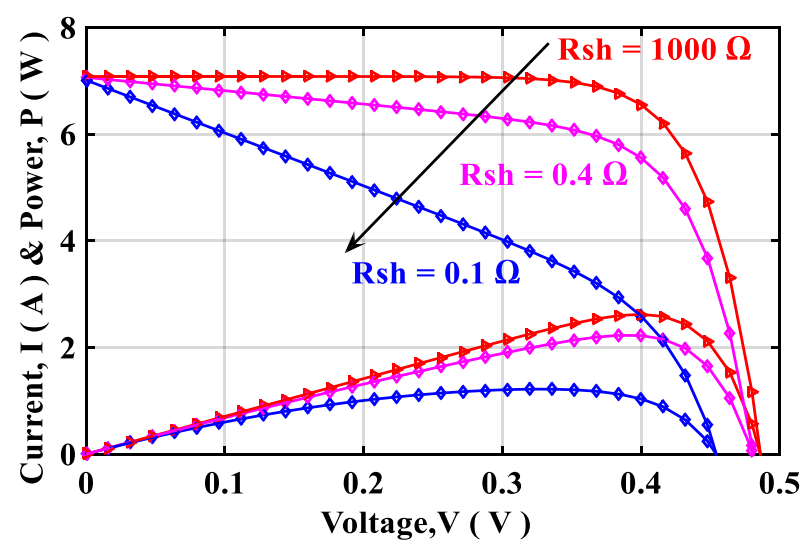

Figure 11. Effect of decreasing shunt resistance on the I-V\& $P$-V characteristics.

From Figure 11 one can see that a high shunt resistance value induces a poor fill factor. The decrease in shunt resistance value causes a decrease at the slope of SC (an increase in horizontal leg) and then severe damage.

It is shown from the above figures that each type of PV fault influences a special part of the characteristics and therefore on specific parameters. This implies to treat each fault in a specific manner, generally. In addition to the above-mentioned PV faults, there are other dangerous electrical failures, which are cited bellow.

\section{A) Ground Fault (GF)}

To prevent electrical shocks in PV plants, the user connects all non-current carrying and metal parts to the common ground. When a high current passes through the metal parts, the photovoltaic installation must stop since this can generate electrical shocks for users. This is known as ground fault [23, 24]. Figure 12 presents a descriptive schematic of a GF example.

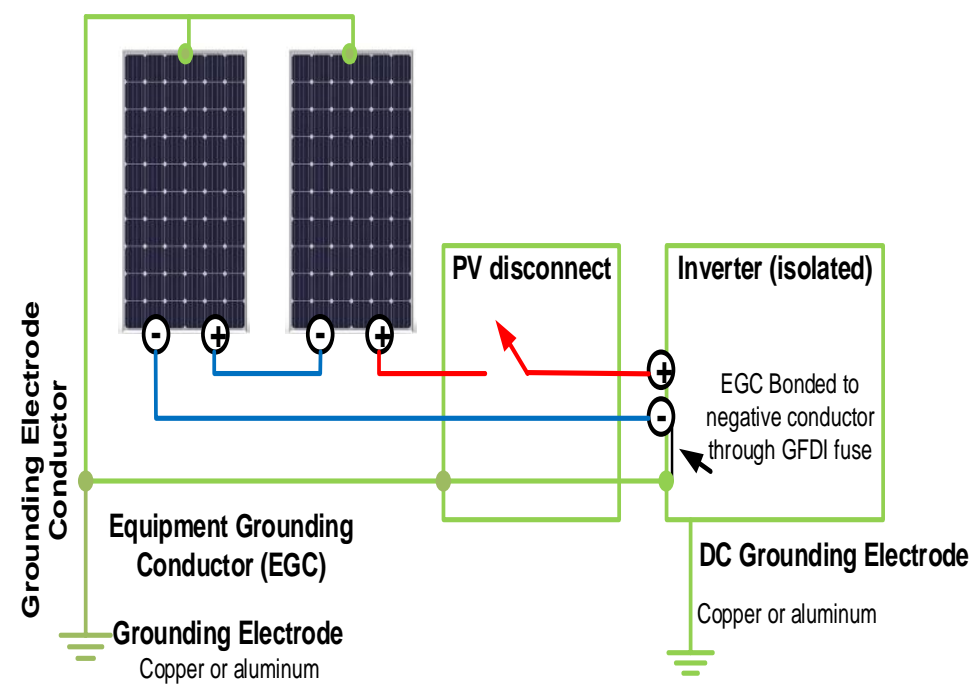

Figure 12. Descriptive schematic of a Ground-Fault (GF). 
B) Line to Line Fault (LLF)

A line-to-line fault, also known as the double ground fault can be defined as a Short-Circuit fault among the PV panel's cables with diverse potential $[25,26]$. Figure 13 presents a descriptive schematic of LLF examples.

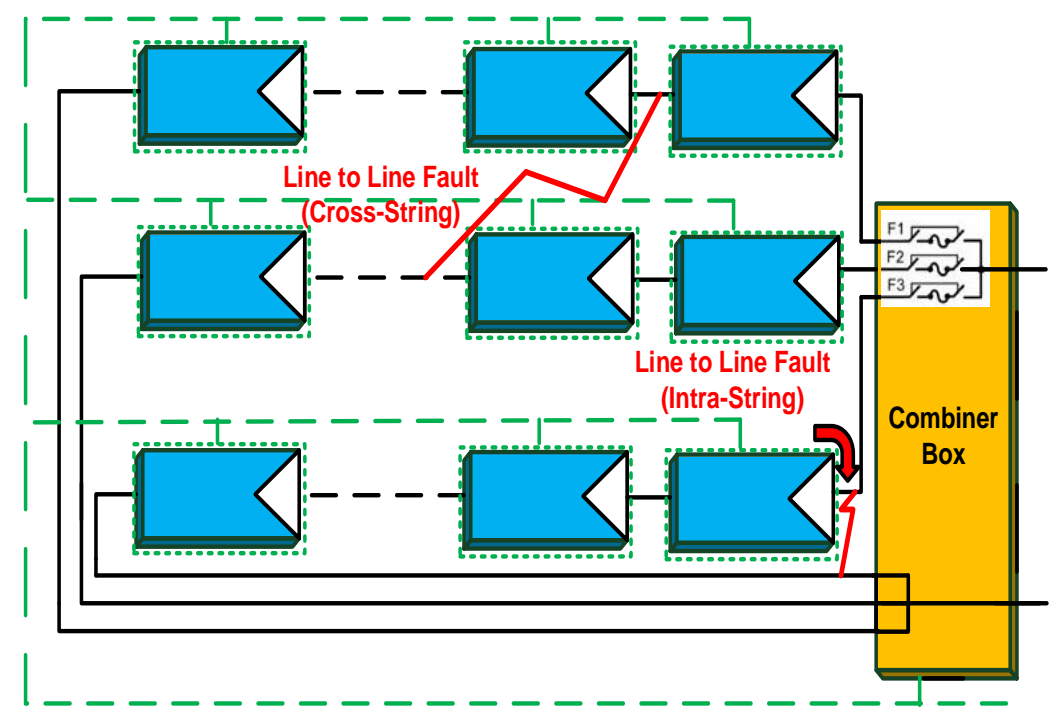

Figure 13. Descriptive schematic of Line-to-Line Fault.

C) Arc Fault (AF)

A rise in temperature leads to combustible material in PVG and therefore the risk of an arc fault. It can be series or parallel AF [27, 28]. Figure 14 presents a descriptive schematic of AF examples.

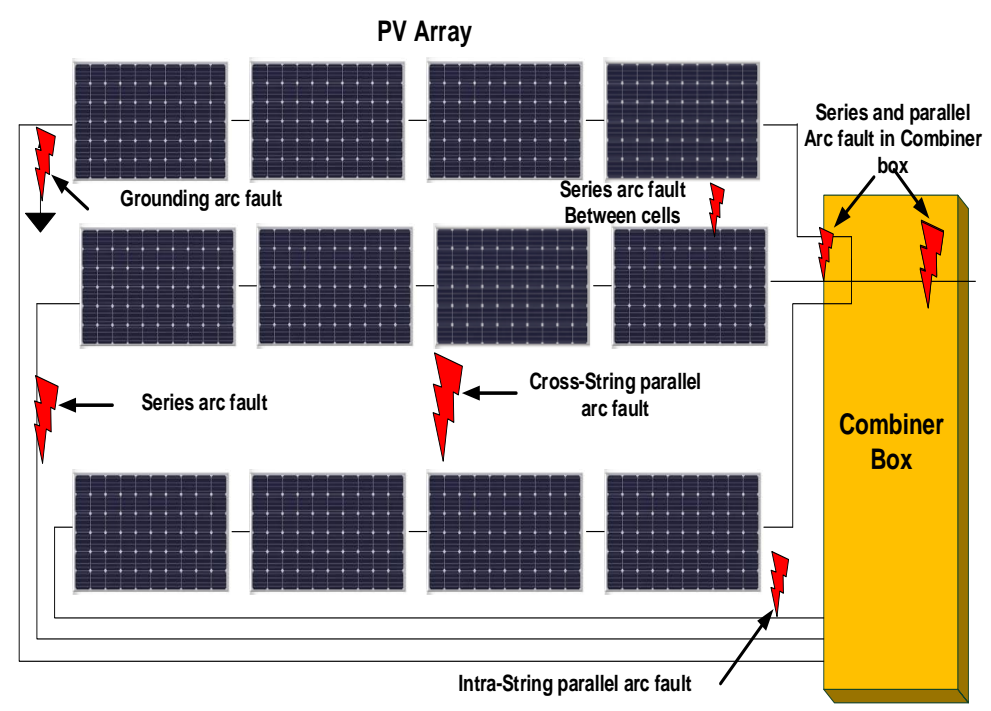

Figure 14. Descriptive schematic of Arc-Fault (AF).

D) Blocking and bypassing diode (BBP)

The blocking and bypassing diodes are integrated into PV panels to protect them. The faults associated with these diodes can be due to Short-Circuit or Open-Circuit [13]. 
E) Junction box fault (JB).

The energy loss stress (ELS) is the major cause of JB faults. Other causes are from bad cabling during installation, or to the ageing effect [11]. Figure 15 gives an example of JB Fault.

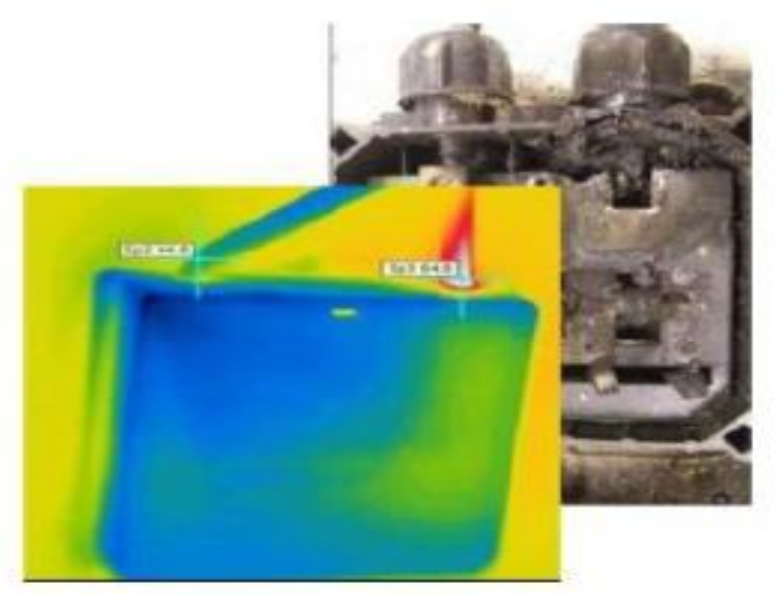

Figure 15. Example of fault in the JB: Corrosion.

The next section detail the elaborated techniques in the literature to diagnose all of the above-mentioned PV faults.

\section{Fault Detection and Diagnosis techniques in PVG}

Researchers have focused in inventing different methods to detect and diagnose failures coming in PV generators in order to prevent main hazards such as fire risks [13], electrical shocks [3], physical danger, and PV panels cracking [15] and so on. FDD-based techniques can be classified into two main categories (visual and electrical). Details are given in what follows.

\subsection{FDD visual-based techniques}

These techniques require human factor intervention [19, 20, 29, and 30]; and consists of inspecting PV generator visually through:

- Thermal imaging process $[31,32]$ by using infrared (IR) camera (e.g. detection of hot spots in PVG, Figure 8).

- Thermal and Electroluminescence (EL) tests [11].

- Photoluminescence (PL) [11].

- Ultrasound scanners and X-ray tomography [11].

\subsection{FDD electrical-based techniques}

These techniques are based on supervised algorithms to be implemented in PV plants [33, 34]. Several electrical-based FDD techniques have been developed [34, 35]. These techniques can be classified also into five groups [13]:

- The first group is based on statistics and signal process [36]: these techniques use signal analysis tools, such as time-domain reflectometry (TDR) [37] and Fourier analysis [38].

- The second group is based on the observation and analysis of the $I-V$ characteristic of the PVG [35]. The $I-V$ curve provides information such as short-circuit current, open-circuit voltage, series and shunt resistors, fill factor and presence of shading and soil. These parameters allow distinguishing several faults.

- The third group is based on power losses analysis [39, 40, 41 and 42]. These fault diagnosis techniques are based on parameters such as thermal and miscellaneous capture losses, which allow generating an 
indicative signal of faults in the PV plant [39]. Besides, other diagnosis techniques are based on the performances ratio, by developing mathematical parameters indicators of voltage and current in [40].

- The fourth group is based on the measured $I-V$ curve $[13,44]$. The techniques compare the real and modelled PVG. The created models are obtained using real measured values of healthy/faulty PVG.

- The fifth group is based on artificial-intelligence techniques. They have been successfully used for the diagnosis of all kinds of renewable energy systems [45], and particularly for PV systems [46]. In [29], [44], [47], [48] and [49], artificial neural networks (ANN) based techniques were used to classify different types of failures occurring in the photovoltaic field. Researchers in this order have developed different model types (multi-layer perceptron, radial basis network, feed forward, recurrent neuralnetwork, etc.) with different structures (number of the hidden layer, number of neurons in the layer) and through the use of a different kind of learning process (supervised/non-supervised). All of the developed ANN-based techniques have proven good accuracy and efficiency in PV diagnosing. In [50], a decision tree-based approach is developed to detect many types of failures (LLF, Shading, and OC). Fuzzy logic controllers are used in [51] and [52] for diagnosing SC, OC, BBP, snow and shading. Combined Neuro-fuzzy based controllers are used in [53] to diagnose earth fault, diode SC, and PS. Besides, the combination of neural networks with a heuristic approach is presented in [54], for the diagnose of SC, ageing, and shading. In [55], the authors used wavelet packets for the detection of faults under low irradiance. It differentiates the shading fault from other ones by the use of variations in voltage array, energy array, and variable impedance. Metaheuristics are developed for FDD in [56] and [57] for diagnosing BBP, SC, disconnection, and shading.

Other methods are presented in [58], [59], and [60]. All of the developed electrical FDD based techniques can be done through offline adaptation (test of the technique's effectiveness) [36] or on-line adaptation at a real-time [60-63].

In what follows, details about the developed FDD electrical-based for each of the cited PV faults presented in section 3 .

a) Shading fault-based FDD:

The measured $I-V$ curve is generally used to diagnose this type of fault [21]. Such as the standard analysis error in [64], vertices principal component analysis (PCA) [65], and discrete wavelet transform (DWT) [66].

b) SC-based FDD:

ANN-based are the most used techniques for failures identification of Short-Circuit fault in PV panels [44], [49]. These techniques have proven good performances in diagnosing SC.

c) OC-based FDD:

The work in [2], identifies and localizes failures at Open-Circuits in PV plant. The ANN-based technique has been developed in [48] with success to diagnose OC fault, using two NNs with a multilayer NN. Furthermore, in [74] a backpropagation neural-network have provided effective detection of OC and other faults.

d) Abnormal degradations-based FDD:

Abnormal degradations have been diagnosed using several techniques in [35, 39]. In [54], a heuristic technique has been proposed for diagnosing several faults and particularly the ageing one. The NNs based are elaborated for diagnosing ageing fault in [74].

e) GF-based FDD:

Some equipment is created to be inserted in the PV plants such as the fuse-based ground-fault-protectiondevice (GFPD) [23]. Some simulations are investigated in [24] to present the limits of GFPD and suggest other solutions. Other techniques for GF are presented in [3].

f) LLF-based FDD:

The over-current-protection-device (OCPD) is inserted in PV plants for protection from LLF [25]. LLF was also treated by the use of a support vector machine (SVM) in [26]. Other techniques for LLF are suggested in [3], [13], and [34]. 
g) AF-based FDD:

Some equipment for protection from AF is inserted such as arc-fault-circuit-interrupter (AFCI) in [67]. Besides, it is treated through time and frequency characteristics of a capacitor current [27] and using wavelet transform and mathematical morphology in [28]. Other techniques for AF are suggested in [3], [13].

h) BBP-based FDD:

Some AI-based techniques are developed to diagnose the BBP fault, such as the fuzzy controller in [52], and meta-heuristics in [57]. Other techniques are proposed in [13], [34].

i) JB-based FDD:

In addition to the control users of the JB, the visual-based techniques give more precision about the health state of JB [13], [34].

The following Table 1 presents the different faults occurring in PVG with their associated FDD techniques.

Table 1. Several PVG faults with their developed diagnosis techniques.

\begin{tabular}{|c|c|}
\hline PVG Faults & Detection and diagnosis used techniques \\
\hline Shading & $\begin{array}{l}\text { AI: decision-tree [50], fuzzy [50-51], neuro- } \\
\text { fuzzy [53], heuristic [54], Meta-heuristic } \\
\text { [56-57] } \\
\text { Standard analysis error in } I-V[64] \\
\text { PCA [65] } \\
\text { DWT [66] }\end{array}$ \\
\hline Short-circuit (SC) & $\begin{array}{c}\text { AI based on I-V curve: ANN [44], [49] } \\
\text { Fuzzy [51-52], heuristic [54], meta-heuristic } \\
{[56,57]}\end{array}$ \\
\hline Open-circuit (OC) & $\begin{array}{c}\text { AI based on I-V curve [48] } \\
\text { Decision-tree [50], Fuzzy [50-51] }\end{array}$ \\
\hline $\begin{array}{l}\text { Abnormal } \\
\text { degradations }\end{array}$ & $\begin{array}{c}\text { Visual inspections and drones } \\
\text { IR, EL, PL }\end{array}$ \\
\hline $\begin{array}{l}\text { Line to Line Fault } \\
\text { (LLF) }\end{array}$ & $\begin{array}{c}\text { Wavelet-Packets [50] } \\
\text { Support vector machine (SVM) [63] }\end{array}$ \\
\hline Arc-Fault (AF) & $\begin{array}{l}\qquad \text { I-V test curve [64] } \\
\text { Frequency domain reflectometry [37] }\end{array}$ \\
\hline $\begin{array}{c}\text { Blocking and } \\
\text { bypassing diode fault } \\
\text { (BBP) }\end{array}$ & AI: Fuzzy [52], Meta-heuristic [56-57] \\
\hline $\begin{array}{l}\text { Junction-box fault } \\
\text { (JB) }\end{array}$ & $\begin{array}{c}\text { User checking } \\
\text { Temperature sense } \\
\text { Visual-based: IR [13] } \\
\text { Multi-meter }\end{array}$ \\
\hline Hot-spot (HS) & Thermal inspections [13]: IR \\
\hline Ageing effect & $\begin{array}{c}\text { AI [51] } \\
\text { Visual inspections }\end{array}$ \\
\hline
\end{tabular}

Moreover, to avoid PV degradations some trending solutions are mentioned bellow.

a) Cleaning PV panels.

Solutions such as cleaning [72, 73] PV panels are used. Cleaning can be dry or wet, related to the type of region. 
$\checkmark$ Dry cleaning is observed in desert regions, due to water rarefaction but it is limited because of scratches on the glass of the PV panels, which appear after the passage of sand wind.

$\checkmark$ Wet cleaning is done in a region rich of water.

PV plants cleaning can be either through a manual manner, automatic, semi-automatic, or using truck.

b) Including protections equipment in PV plants.

To protect PVG from overcurrent, fuses and overcurrent protection device as OCPD [50] are inserted. Besides, devices such as GFPD [23] is capable of GF detection, fault current interruption, indication, and provide fire hazard prevention. Furthermore, equipment named AFCI is developed in [67] to protect PV plants from an arc fault.

c) Tele-monitoring

Controlling and diagnosing the PVG from long distance using new smart protocols such as ZigBee technology [74] and Internet of Thing (IoT) [75].

Cost reduction is required for any envisaged solutions for diagnosing PV generators. In industry, some solutions are integrated into PV plants. Some of them have been implemented and some others have not been implemented because of their high complexity or great cost estimation. In this order, cost estimation, efficiency, robustness, low complexity of implementation, integration in the whole PV system have a major influence in the choice of the appropriate FDD technique for diagnosing the faults in PVG.

\section{Process of FDD techniques in PVG}

Many anomalies, degradations, and faults, presented above, can occur in PV generators. A challenge is required to detect automatically these faults and diagnose them in early stages before dangerous risks and severe damages appear. PV plants inspections and alarms allow the users, when failures are detected, to take decisions to correct the process. In general, operators do some visual PV inspections (detection of bubbles, delamination, detachment of the frame, discoloring) before system start-up. As for thermal fault and defects, like a hotspot, it is necessary to use instruments such as infrared (IR) camera mounted on drones [68-70] for image thermography inspections to detect hotter areas within PVG. Drones can detect anomalies with high precision. This process is also required for electrical-based FDD, by using the images stored in a database, taken from drones. Researchers developed further techniques analysis, as electrical FDD-based, to be implemented with the PV plant to detect, diagnose, correct failures, and protect the system. The major faults diagnosis steps, using FDD electrical-based techniques, are cited bellow:

- Measurements through sensors and data acquisition system.

- Modeling of the health and fault states.

- Detection and localization of faults.

- Classification and decision.

- Correction, protection, and adaptation.

\subsection{Proposed FDD electrical-based}

For a well and clarified explanation of the process of the FDD electrical-based techniques [71], we have opted for an approach to diagnose shading fault in a PV generator installed on the roof of Multi-SourcesSystem laboratory at UDES, using neural-networks (NN). PVG power is the parameter to be processed. The descriptive schematic of the elaborated FDD electrical-based technique is presented in Figure 16. 


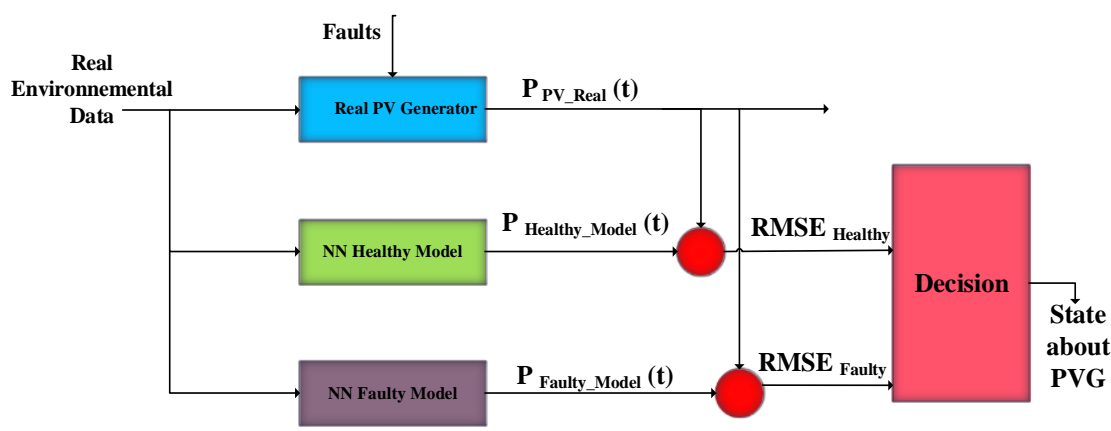

Figure 16. Descriptive schematic of the proposed FDD electrical-based in the PV generator.

The major steps of the developed FDD electrical-based for PVG are detailed in the following points.

1) The real data acquisition.

Some measurements have been done, through an acquisition work for obtaining real environmental (temperature and irradiance) and electrical (current and voltage from the battery) data. They are required at the first step of PV diagnosis.

2) NN-based Modeling and validation.

Using a database of several days two neural-network models are created for healthy and faulty (shaded) PV generator respectively. From the introduced real data (temperature, irradiance, battery_current, and battery_voltage), power models for healthy and faulty PVG are elaborated (Figure 16).

3) Detection \& localization of faults.

a- Reading of real data

In specific two days $(11 / 03 / 2020 \& 26 / 11 / 2020)$ for both healthy and faulty PVG respectively, read of real acquired data to be diagnosed.

b- Simulation using the two models

In Matlab environment, simulate of healthy and faulty models behavior using the real data as inputs. At this step, the obtained results are illustrated in Figure17 and Figure 18.

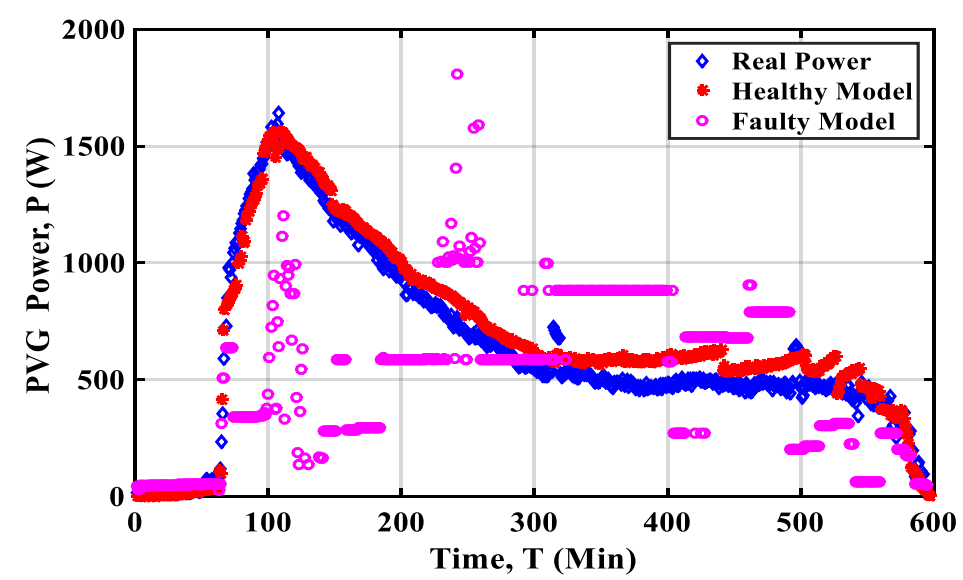

Figure 17. Real and modelled data for power, in a healthy PVG (11/03/2020). 


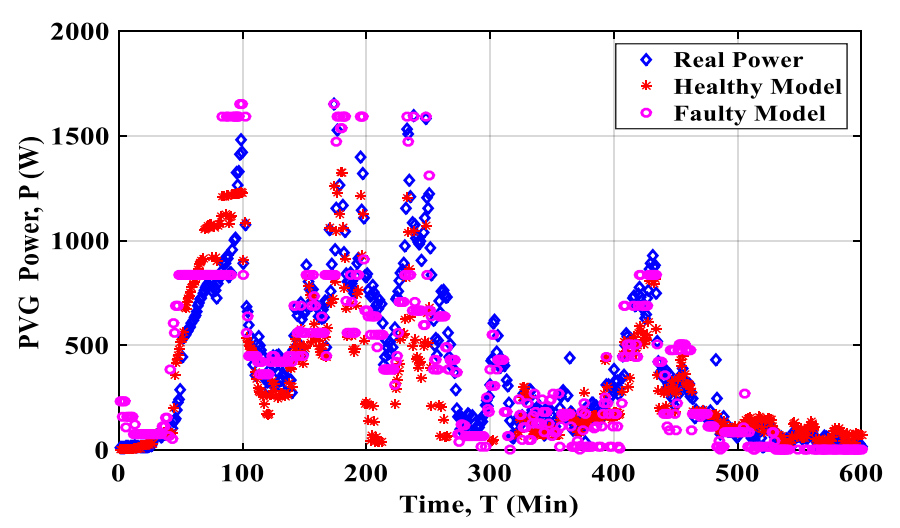

Figure 18. Real and modeled data for power, in a faulty PVG (shading a single PV module in the PVG) (26/10/2020).

It is observed from Figure 17 that the healthy generated model is the nearest one from the real data. Besides, it is observed from Figure 18 that the faulty (shaded) generated model is the nearest one from the real data.

4) Decision about diagnosis

Comparing the results of the two obtained models with the measured power of the real PVG using Root Mean Square Errors (RMSE), which is calculated between the real power and both of the healthy and faulty modeled powers through the following expression.

$$
R M S E=\sqrt{\frac{1}{N} \sum_{i=1}^{N}\left(\mathrm{P}_{\text {Real }}(\mathrm{i})-\mathrm{P}_{\text {Model }}(\mathrm{i})\right)^{2}}
$$

Where $N$ : is the number of data.

Based on the values of RMSE $E_{\text {Healthy }}$ and RMSEFaulty, a decision is made about the state of the PV generator, as shown in Figure 19 and Figure 20 bellow.

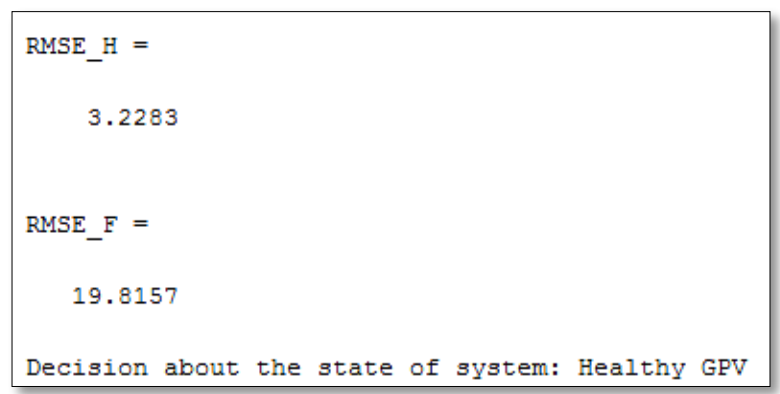

Figure 19. RMSE command window results for healthy PVG.

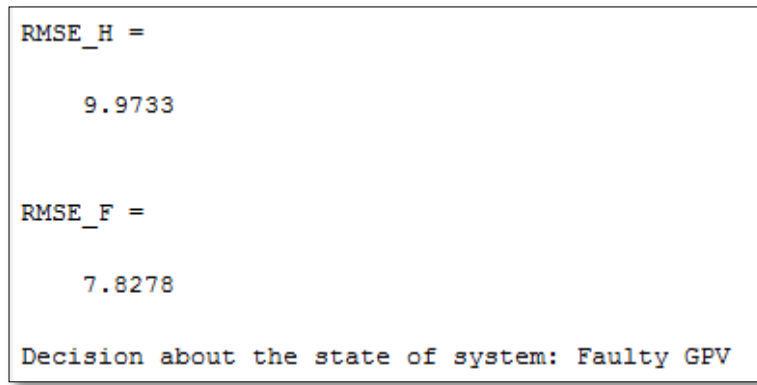

Figure 20. RMSE command window results for faulty PVG. 
The lowest value of RMSE allows deciding the health state of the system. As in Figure 19, the PVG was healthy in the day of $(11 / 03 / 2020)$ relatively to the lowest value of RMSE $E_{\text {Healthy }}$ compared to RMSE $E_{\text {Faulty. }}$ In contrast, the PVG of Figure 20 was faulty in the day of (26/10/2020) relatively to the lowest value obtained for $\mathrm{RMSE}_{\text {Faulty }}$ compared to RMSE $\mathrm{Healthy}_{\text {. }}$

For classifying with high accuracy and effectiveness of different other faults occurring in PVG, more sophisticated techniques exist in the literature, which can be an extension of this developing technique as perspective work.

\section{Conclusion}

Quite recently, considerable attention has been paid to the topic of monitoring, supervision, and faults diagnosis occurring in PV generators generally and in PV plants particularly. Improving each part of this research field leads to minimize energy losses, improve power supply reliability, and safeguard PV plants from degradations, fire hazards, and many other dangerous risks. This paper has presented a comprehensive study on the diagnosis of faults occurring in the PV generator. It presented the major forms of degradations in PVG. Gives details about the different types of PV faults taking into consideration their causes. Various FDD techniques have been presented. Some envisaged diagnosis solutions have been discussed. Some criteria (low cost, simple implementation, high efficiency, robustness) are required for any envisaged solutions for diagnosing a PV generator/plant. A focus was done to a proposed approach for a shading fault diagnosis using the neural network-based method. Based on the obtained results, it can be concluded that the developed technique has shown good performances. This electrical FDD-based technique was done offline to test the effectiveness of the NN based models developed herein. Authors wish to extend and develop this technique to an online application for different faults in a future work.

\section{References}

[1] Arnulf Jäger-Waldau. Snapshot of Photovoltaics-February 2020. Energies 2020, 13, 930; doi: 10.3390/en13040930.

[2] Y. H. a. W. Cao, "Theoretical Analysis and Implementation of Photovoltaic Fault Diagnosis," in Book Renewable Energy - Utilisation and System Integration, ed, May 11th 2016.

[3] M. K. Alam, F. Khan, J. Johnson, and J. Flicker, "A Comprehensive Review of Catastrophic Faults in PV Arrays: Types, Detection, and Mitigation Techniques," IEEE Journal of Photovoltaics, vol. 5, pp. 982997, 2015.

[4] Branco, Gonçalves, and A. Costa, "Tailored Algorithms for Anomaly Detection in Photovoltaic Systems," Energies, vol. 13, p. 225, 01/02 2020.

[5] M. A. Quintana, D. L. King, T. J. McMahon, and C. R. Osterwald, "Commonly observed degradation in field-aged photovoltaic modules," in Conference Record of the Twenty-Ninth IEEE Photovoltaic Specialists Conference, 2002., 2002, pp. 1436-1439.

[6] S. Lindig, I. Kaaya, K. Weiss, D. Moser, and M. Topic, "Review of Statistical and Analytical Degradation Models for Photovoltaic Modules and Systems as Well as Related Improvements," IEEE Journal of Photovoltaics, vol. 8, pp. 1773-1786, 2018.

[7] H. Laukamp, Schoen, T., Ruoss, D., "Reliability Study of Grid Connected PV Systems, Field Experience and Recommended Design Practice," p. 31, 2002.

[8] J. D. G. Heinrich Haeberlin, Berner Fachhochschule, "Gradual Reduction of PV Generator Yield due to Pollution," presented at the 2nd World Conference on Photovoltaic Solar Energy Conversion, Vienna, Austria, Published 1998.

[9] C. Deline, "Partially shaded operation of multi-string photovoltaic systems," in 2010 35th IEEE Photovoltaic Specialists Conference, 2010, pp. 000394-000399.

[10] T. J. Silverman, M. G. Deceglie, I. Subedi, N. J. Podraza, I. M. Slauch, V. E. Ferry, et al., "Reducing Operating Temperature in Photovoltaic Modules," IEEE Journal of Photovoltaics, vol. 8, pp. 532-540, 2018.

[11] M. Köntges, S. Kurtz, C. Packard, U. Jahn, K. Berger, K. Kato, et al., Review of Failures of Photovoltaic Modules, 2014. 
[12] M. Coello and L. Boyle, "Simple Model for Predicting Time Series Soiling of Photovoltaic Panels," IEEE Journal of Photovoltaics, vol. 9, pp. 1382-1387, 2019.

[13] A. Mellit, G. M. Tina, and S. A. Kalogirou, "Fault detection and diagnosis methods for photovoltaic systems: A review," Renewable and Sustainable Energy Reviews, vol. 91, pp. 1-17, 2018/08/01/ 2018.

[14] D. S. Pillai and N. Rajasekar, "A comprehensive review on protection challenges and fault diagnosis in PV systems," Renewable and Sustainable Energy Reviews, vol. 91, pp. 18-40, 2018/08/01/ 2018.

[15] E. L. Meyer and E. E. v. Dyk, "Assessing the reliability and degradation of photovoltaic module performance parameters," IEEE Transactions on Reliability, vol. 53, pp. 83-92, 2004.

[16] R. K. Jones, A. Baras, A. A. Saeeri, A. A. Qahtani, A. O. A. Amoudi, Y. A. Shaya, et al., "Optimized Cleaning Cost and Schedule Based on Observed Soiling Conditions for Photovoltaic Plants in Central Saudi Arabia," IEEE Journal of Photovoltaics, vol. 6, pp. 730-738, 2016.

[17] P. Guerriero and S. Daliento, "Toward a Hot Spot Free PV Module," IEEE Journal of Photovoltaics, vol. 9, pp. 796-802, 2019.

[18] A. Woyte, J. Nijs, and R. Belmans, "Partial shadowing of photovoltaic arrays with different system configurations: literature review and field test results," Solar Energy, vol. 74, pp. 217-233, 2003/03/01/ 2003.

[19] D. King, M. Quintana, J. Kratochvil, D. Ellibee, and B. Hansen, "Photovoltaic module performance and durability following long-term field exposure," Progress in Photovoltaics: Research and Applications, vol. 8, pp. 241-256, 03/01 2000.

[20] M. A. Munoz, M. C. Alonso-García, N. Vela, and F. Chenlo, "Early degradation of silicon PV modules and guaranty conditions," Solar Energy, vol. 85, pp. 2264-2274, 2011/09/01/ 2011.

[21] Tingting Pei and Xiaohong Hao. A Fault Detection Method for Photovoltaic Systems Based on Voltage and Current Observation and Evaluation. Energies 2019, 12, 1712; doi: 10.3390/en12091712.

[22] E. Kaplani. Degradation Effects in sc---Si PV Modules Subjected to Natural and Induced Ageing after Several Years of Field Operation. Journal of Engineering Science and Technology Review 5 (4) (2012) 18-23 Special Issue on Renewable Energy Systems.

[23] William Brooks. "Field Guide for Testing Existing Photovoltaic Systems for Ground Faults and Installing Equipment to Mitigate Fire Hazards". NREL/SR-5D00-65050 October 2015.

[24] Jack Flicker and Jay Johnson. "Photovoltaic Ground Fault Detection Recommendations for Array Safety and Operation". Solar Energy, Vol. 140, pp. 34-50, 15 Dec. 2016.

[25] Ye Zhao, Robert Lyons. "Line-Line Fault Analysis and Protection Challenges in Solar Photovoltaic Arrays". IEEE Transactions on Industrial Electronics, VOL. 60, NO. 9, SEPTEMBER 2013.

[26] Zhehan Yi, Amir H. Etemadi. "A Novel Detection Algorithm for Line-to-Line Faults in Photovoltaic (PV) Arrays Based on Support Vector Machine (SVM)".

[27] Qing Xionga,b, Shengchang Jia, Xiaojun Liua, Xianyong Fengb, Fan Zhanga, Lingyu Zhua, Angelo L. Gattozzib, Robert E. Hebner. "Detecting and localizing series arc fault in photovoltaic systems based on time and frequency characteristics of capacitor current". Solar Energy 170 (2018) 788-799.

[28] Medhawa Weerasekara. "DC Arc Faults In Photovoltaic Systems". Queensland University of Technology, Thesis 2019.

[29] R. Pierdicca, E. Malinverni, F. Piccinini, M. Paolanti, A. Felicetti, and P. Zingaretti, "Deep convolutional neural network for automatic detection of damaged photovoltaic cells" ISPRS - International Archives of the Photogrammetry, Remote Sensing and Spatial Information Sciences, vol. XLII-2, pp. 893-900, 05/30 2018.

[30] Naveen Venkatesh S and V Sugumaran. Fault diagnosis of visual faults in photovoltaic modules: A Review. International journal of green energy. https://doi.org/10.1080/15435075.2020.1825443.

[31] Hyewon Jeon. Thermal image analysis for fault detection and diagnosis of PV systems. West Lafayette, Indiana. Thesis, May 2020.

[32] Karuppiah Natarajan, B. Praveen Kumar, Vankadara Sampath Kumar. Fault Detection of Solar PV system using SVM and Thermal Image Processing. International journal of renewable energy research, Vol.10, No.2, June 2020.

[33] R. Platon, J. Martel, N. Woodruff, and T. Y. Chau, "Online Fault Detection in PV Systems," IEEE Transactions on Sustainable Energy, vol. 6, pp. 1200-1207, 2015. 
[34] A. Y. Appiah, X. Zhang, B. B. K. Ayawli, and F. Kyeremeh, "Review and Performance Evaluation of Photovoltaic Array Fault Detection and Diagnosis Techniques," International Journal of Photoenergy, vol. 2019, p. 19, 2019.

[35] Tingting Pei and Xiaohong Hao. A Fault Detection Method for Photovoltaic Systems Based on Voltage and Current Observation and Evaluation. Energies 2019, 12, 1712; doi: 10.3390/en12091712.

[36] S. Vergura, G. Acciani, V. Amoruso, G. E. Patrono, and F. Vacca, "Descriptive and Inferential Statistics for Supervising and Monitoring the Operation of PV Plants," IEEE Transactions on Industrial Electronics, vol. 56, pp. 4456-4464, 2009.

[37] T. Takashima, J. Yamaguchi, and M. Ishida, "Fault detection by signal response in PV module strings," in 2008 33rd IEEE Photovoltaic Specialists Conference, 2008, pp. 1-5.

[38] J. Johnson, S. Kuszmaul, W. Bower, and D. Schoenwald, Using PV module and line frequency response data to create robust arc fault detectors, 2011.

[39] C. Aissa, "Analysis, diagnosis and fault detection in photovoltaic systems," Thesis doctorals, Universitat Politècnica de Catalunya, 2010.

[40] Mário Filipe Aires da Silva. Analysis of new indicators for Fault detection in grid connected PV systems for BIPV applications. UNIVERSIDADE DE LISBOA, 2014.

[41] B. Kang, S. Kim, S. Bae, and J. Park, "Diagnosis of Output Power Lowering in a PV Array by Using the Kalman-Filter Algorithm," IEEE Transactions on Energy Conversion, vol. 27, pp. 885-894, 2012.

[42] A. Chouder and S. Silvestre, "Automatic supervision and fault detection of PV systems based on power losses analysis," Energy Conversion and Management, vol. 51, pp. 1929-1937, 2010/10/01/ 2010.

[43] M. Miwa, S. Yamanaka, H. Kawamura, H. Ohno, and H. Kawamura, "Diagnosis of a Power Output Lowering of PV Array with a (-dI/dV)-V Characteristic," in 2006 IEEE 4th World Conference on Photovoltaic Energy Conference, 2006, pp. 2442-2445.

[44] W. Chine, A. Mellit, V. Lughi, A. Malek, G. Sulligoi, and A. Massi Pavan, "A novel fault diagnosis technique for photovoltaic systems based on artificial neural networks," Renewable Energy, vol. 90, pp. 501-512, 2016/05/01/ 2016.

[45] J. Bermejo, J. Fernández, F. Polo, and A. Crespo Marquez, "A Review of the Use of Artificial Neural Network Models for Energy and Reliability Prediction. A Study of the Solar PV, Hydraulic and Wind Energy Sources," Applied Sciences, vol. 9, p. 1844, 05/05 2019.

[46] A. Mellit and S. A. Kalogirou, "Artificial intelligence techniques for photovoltaic applications: A review," Progress in Energy and Combustion Science, vol. 34, pp. 574-632, 2008/10/01/ 2008.

[47] W. Yuchuan, L. Qinli, and S. Yaqin, "Application of BP neural network fault diagnosis in solar photovoltaic system," in 2009 International Conference on Mechatronics and Automation, 2009, pp. 2581-2585.

[48] H.-R. Hwang, B.-S. Kim, T.-H. Cho and I.-S. Lee, "Implementation of a Fault Diagnosis System Using Neural Networks for Solar Panel," International Journal of Control, Automation and Systems, vol. 17, pp. 1050-1058, 2019/04/01 2019.

[49] Syafaruddin, E. Karatepe, and T. Hiyama, "Controlling of artificial neural network for fault diagnosis of photovoltaic array," in 2011 16th International Conference on Intelligent System Applications to Power Systems, 2011, pp. 1-6.

[50] Y. Zhao, L. Yang, B. Lehman, J. d. Palma, J. Mosesian, and R. Lyons, "Decision tree-based fault detection and classification in solar photovoltaic arrays," in 2012 Twenty-Seventh Annual IEEE Applied Power Electronics Conference and Exposition (APEC), 2012, pp. 93-99.

[51] S. A. Zaki, H. Zhu, and J. Yao, "Fault detection and diagnosis of photovoltaic system using fuzzy logic control," E3S Web Conf., vol. 107, p. 02001, 2019.

[52] Q. Zhao, S. Shao, L. Lu, X. Liu, and H. Zhu, "A New PV Array Fault Diagnosis Method Using Fuzzy CMean Clustering and Fuzzy Membership Algorithm," Energies, vol. 11, p. 238, 01/19 2018.

[53] L. Bonsignore, M. Davarifar, A. Rabhi, G. M. Tina, and A. Elhajjaji, "Neuro-Fuzzy Fault Detection Method for Photovoltaic Systems," Energy Procedia, vol. 62, pp. 431-441, 2014/01/01/ 2014.

[54] Z. L. D. W. L. T. J. R. Z. Liu, "A Heuristic Diagnostic Method for a PV System: Triple-Layered Particle Swarm Optimization-Back-Propagation Neural Network," Energies, MDPI, Open Access Journal, vol. vol. 10(2), pp. 1-11, 2017.

[55] B. P. Kumar, G. S. Ilango, M. J. B. Reddy, and N. Chilakapati, "Online Fault Detection and Diagnosis in Photovoltaic Systems Using Wavelet Packets," IEEE Journal of Photovoltaics, vol. 8, pp. 257-265, 2018. 
[56] Y. Wu, Z. Chen, L. Wu, P. Lin, S. Cheng, and P. Lu, "An Intelligent Fault Diagnosis Approach for PV Array Based on SA-RBF Kernel Extreme Learning Machine," Energy Procedia, vol. 105, pp. 1070-1076, 2017/05/01/ 2017.

[57] O. Hachana, G. Tina, and K. Hemsas, "PV array Fault Diagnostic Technique for BIPV Systems Oussama 2016," ed, 2016.

[58] D. Sera, R. Teodorescu, and P. Rodriguez, "Photovoltaic module diagnostics by series resistance monitoring and temperature and rated power estimation," in 2008 34th Annual Conference of IEEE Industrial Electronics, 2008, pp. 2195-2199.

[59] J. D. Bastidas-Rodriguez, E. Franco, G. Petrone, C. A. Ramos-Paja, and G. Spagnuolo, "Quantification of photovoltaic module degradation using model based indicators," Mathematics and Computers in Simulation, vol. 131, pp. 101-113, 2017/01/01/ 2017.

[60] I. Santiago, D. Trillo Montero, J. J. Luna Rodríguez, I. M. Moreno Garcia, and E. J. Palacios Garcia, "Graphical Diagnosis of Performances in Photovoltaic Systems: A Case Study in Southern Spain," Energies, vol. 10, p. 1964, 2017.

[61] H. Lin, Z.-C. Chen, L. Wu, P. Lin, and S. Cheng, On-line Monitoring and Fault Diagnosis of PV Array Based on BP Neural Network Optimized by Genetic Algorithm, 2015.

[62] G. Tina, F. Cosentino, and C. Ventura, "Monitoring and Diagnostics of Photovoltaic Power Plants," ed, 2016, pp. 505-516.

[63] Syafaruddin, and Donald S. Zinger. "Review on Methods of Fault Diagnosis in Photovoltaic System Applications". Journal of Engineering Science and Technology Review 12 (5) (2019) 53 - 66.

[64] Mickael Bressan, Youssef El Basri, A.G. Galeano, Corinne Alonso. A shadow fault detection method based on the standard error analysis of I-V curves. Renewable Energy, Elsevier, 2016, Renewable Energy, 99, pp.1181-1190. 10.1016/j.renene.2016.08.028.

[65] S. Fadhel, Claude Delpha, Demba Diallo, I. Bahri, A. Migan, M. Trabelsi, M.F. Mimouni. PV shading fault detection and classification based on I-V curve using principal component analysis: Application to isolated PV system. Solar Energy, Elsevier, 2019, 179, pp.1-10.

[66] M. Davarifar, A. Rabhi, A. Hajjaji and E. Kamal, Z. Daneshifar. Partial Shading Fault Diagnosis in PV System With Discrete Wavelet Transform (DWT). 3rd International Conference on Renewable Energy Research and Applications. Milwakuee, USA 19-22 Oct 2014.

[67] Kenneth M. Armijo, Jay Johnson, Michael Hibbs and Armando Fresquez. "Characterizing Fire Danger from Low-Power Photovoltaic Arc-Faults". SAND2014-4593C.

[68] Alessandro Niccolai, Francesco Grimaccia, and Sonia Leva. "Advanced Asset Management Tools in Photovoltaic Plant Monitoring: UAV-Based Digital Mapping”. Energies 2019, 12, 4736 ; doi:10.3390/en12244736.

[69] Yahya Zefri, Achraf ElKettani, Imane Sebari, and Sara Ait Lamallam. "Thermal Infrared and Visual Inspection of Photovoltaic Installations by UAV Photogrammetry-Application Case: Morocco". Drones 2018, 2, 41 ; doi : 10.3390/drones2040041.

[70] Elias Roumpakias, Fotis Bouroutzikas, Anastassios Stamatelos. "On-site Inspection of PV Panels, Aided by Infrared Thermography”. Advances in Applied Sciences. Vol. 1, No. 3, 2016, pp. 53-62.

[71] Sobhani-Tehrani, E.; Khorasani, K. "Fault Diagnosis of Nonlinear Systems Using a Hybrid Approach". Springer, Chapitre 2. 2009.

[72] Mohammed Al-Housani, Yusuf Bicer, and Muammer Koç. "Assessment of Various Dry Photovoltaic Cleaning Techniques and Frequencies on the Power Output of CdTe-Type Modules in Dusty Environments". Sustainability 2019, 11, 2850; doi: 10.3390/su11102850.

[73] Saravanan V. S, Darvekar S. K. Solar Photovoltaic Panels Cleaning Methods: A Review. International Journal of Pure and Applied Mathematics Volume 118 No. 242018.

[74] Ling Chen, Wei Han, Hai-Tao Li, Zi-Kun Xu, Jing-Wei Zhang, Xiang Cao. Long distance wireless fault diagnosis for photovoltaic modules based on back propagation neural network. The International Journal of Electrical Engineering \& Education. 2020.

[75] Youssef Cheddadi, Hafsa Cheddadi, Fatima Cheddadi1 • Fatima Errahimi1 • Najia Es-sbai1. "Design and implementation of an intelligent low-cost IoT solution for energy monitoring of photovoltaic stations". SN Applied Sciences (2020). 